\title{
T Wave Duration Aggregate
}

National Cancer Institute

\section{Source}

National Cancer Institute. I Wave Duration Aggregate. NCI Thesaurus. Code C117812.

An aggregate T wave duration value based on the measurement of T wave duration intervals from multiple beats within a sing le ECG. The method of aggregation, which can vary, is typically a measure of central tendency such as the mean. (CDISC) 